\title{
A PERSPECTIVA DE GÊNERO NA CONSTRUÇÃO DA SUSTENTABILIDADE
}

\section{Gender Perspective On Sustainability Of Construction}

\author{
Marcia Beraldo Lagos ${ }^{15}$ \\ Frank Silvano Lagos ${ }^{16}$ \\ Nilvânia Aparecida Mello ${ }^{17}$ \\ Hieda Maria Pagliosa Corona ${ }^{18}$
}

\section{Resumo}

Entre os diversos temas ligados ao desenvolvimento sustentável, no contexto atual, o papel da mulher para a sustentabilidade vem ganhando espaço nas discussões, de tal forma que na Rio +20 organizou-se um evento paralelo chamado ONU Mulheres. A associação entre mulher e meio ambiente iniciouse com a criação do conceito de ecodesenvolvimento, que procura expor uma concepção de desenvolvimento adaptado às áreas rurais dos países subdesenvolvidos e uma utilização criteriosa dos recursos, objetivando a diminuição dos impactos ambientais. As mulheres deram contribuições históricas para a construção da sustentabilidade, dentre estas contribuições podemos citar Rachel Carson, Gro Brundtland, Wangari Maathai, Hazel Henderson, Vandana Shiva e Marina Silva. O ecofeminismo pode ser

15 Mestranda em Desenvolvimento Regional pela Universidade Tecnológica Federal do Paraná, campus Pato Branco. Docente no Instituto Federal do Paraná, campus Palmas. email: marcia.lagos@ifpr.edu.br

16 Mestre em Agronomia, docente no Instituto Federal do Paraná - Campus Palmas e-mail: frank.lagos@ ifpr.edu.br

Doutora em Ciência do Solo, docente no Programa de Pós Graduação em Desenvolvimento Regional da Universidade Tecnológica Federal do Paraná, campus Pato Branco e-mail: nilvania@utfpr.edu.br

18 Doutora em Meio Ambiente e Desenvolvimento, docente no Pós Graduação em Desenvolvimento Regional da Universidade Tecnológica Federal do Paraná, campus Pato Branco e-mail: pagliosa@utfpr. edu.br 
definido como uma escola de pensamento que tem orientado movimentos ambientalistas e feministas, em várias partes do mundo, procurando fazer uma interconexão entre a dominação da natureza e a dominação das mulheres. As políticas públicas, na maioria das vezes, não consideram a existência das desigualdades sociais entre o masculino e o feminino, penalizando as mulheres, que ficam à margem do processo. A busca da sustentabilidade requer a construção de novas formas de organização e de convívio, fundamentadas no equilíbrio, harmonia e reciprocidade entre os seres humanos independente do gênero e deles com as demais espécies da natureza.

Palavras-chaves: Gênero, Desenvolvimento Sustentável; Sustentabilidade;

\section{Abstract}

Among many topics related to sustainable development in the current context, the role of women in sustainability issues has gained importance in the discussions, so that the Rio +20 organized a parallel event called ONU Women. The association between women and the environment began with the creation of the concept of eco-development, which seeks to expose a development concept adapted to the rural areas of developing countries and a very specific way of using resources in order to decrease environmental impacts. Women made historic contributions to the construction of sustainability, and some of those women are Rachel Carson, Gro Brundtland, Wangari Maathai, Hazel Henderson, Vandana Shiva and Marina Silva. Ecofeminism can be defined as a school of thought that has guided environmental and feminist movements in various parts of the world, seeking to make an interconnection between the domination of nature and domination of women. Public policies, in most cases, do not consider the existence of social inequalities between male and female, penalizing women who have become marginalized in the process. The pursuit of sustainability requires the construction of new forms of organization and interaction, based on the balance, harmony and reciprocity among human beings regardless of their gender and with other species of nature.

Key-words: Gender; Sustainable Development; Sustainability;

\section{Introdução}


A conceituação de desenvolvimento sustentável, tal como conhecida hoje, surgiu no final do século XX, para traduzir várias ideias e preocupações relacionadas aos efeitos deletérios ao planeta advindo do crescimento econômico historicamente confundido com desenvolvimento econômico. De acordo com Leff (2005), este processo de expansão da racionalidade econômica culminou com saturação do ambiente, problemas econômicos e sociais. A lógica da globalização calcada em objetivos puramente econômicos nos conduziu à impossibilidade de pensar e agir de forma a limitar o crescimento de acordo com as leis da vida, da natureza e da cultura. Esta sobre-economização do mundo induziu a uma homogeneização dos padrões de produção e de consumo, contra uma sustentabilidade planetária fundada na diversidade ecológica e cultural. Uma das primeiras organizações a apontar os riscos do crescimento econômico contínuo foi o Clube de Roma em 1972. No mesmo ano, a Organização das Nações Unidas (ONU) realizou a Conferência de Estocolmo, que abordou problemas ambientais decorrentes da poluição atmosférica, crescimento populacional e crescimento versus desenvolvimento. Em 1974, surge a proposta do ecodesenvolvimento, formulada por intelectuais como Sachs, Leff e Strong, que incorporou ao conceito de sustentabilidade suas múltiplas dimensões: econômica, social, cultural, política e ambiental. Todavia, o termo 'sustentável' aparece pela primeira vez no informe das Nações Unidas: Nosso Futuro Comum (Comissão Mundial sobre o meio ambiente e desenvolvimento, 1991), conhecido como informe Brundtland em 1987. O objetivo deste trabalho é discutir o conceito de desenvolvimento sustentável e analisar como se dá a relação da mulher com a sustentabilidade e a incorporação de gênero pelas políticas públicas voltadas para a sustentabilidade.

\section{A mulher e a sustentabilidade}

A associação entre mulher e meio ambiente iniciou-se a com a criação do conceito de ecodesenvolvimento, termo criado por Maurice Strong, na década de 70 e depois ampliado por Ignacy Sachs que incorporou as dimensões sociais, econômicas, culturais, de gestão participativa e ética ao termo. 
conceito inicial de ecodesenvolvimento procurava expor uma concepção de desenvolvimento adaptado às áreas rurais dos países subdesenvolvidos e a uma utilização criteriosa dos recursos, objetivando a diminuição dos impactos ambientais (LAYRARGUES, 1997). Essa preocupação destacou dois importantes fatores que demonstraram uma maior afinidade da mulher com a natureza do que o homem: a situação da mulher nas zonas rurais de países pobres frente à migração do homem para os centros urbanos em busca de emprego realçou a importância da mulher quando da concepção e implantação de planos e projetos ambientalistas. Outro importante fator da associação entre mulher e meio ambiente foi mais de caráter cultural, com a representação social da terra como ente feminino (FIÚZA, 1997). Segundo Garcia, (1992) parte significativa da literatura sobre mulher e meio ambiente sugere haver alguma coisa fundamental ou inata nessa relação, com as mulheres sendo vistas como tendo mãos que curam que nutrem e cuidam do meio ambiente, visão contestada por outros autores, como discutiremos na sequência.

Após a conferência sobre o Meio Ambiente Humano realizada em Estocolmo, em 1972, a percepção da mulher como agente ambientalista tornou-se internacionalmente mais visível. Quando, pela primeira vez o problema da degradação ambiental nos países desenvolvidos foi colocado como uma necessidade que exigia integrar a preocupação com a defesa do meio ambiente no próprio processo de desenvolvimento. Após essa conferência, a Assembleia Geral da ONU resolveu declarar 1975 como o Ano Internacional da Mulher e realizar uma conferência mundial específica com o objetivo de formular recomendações para promover a sua plena igualdade e participação na vida social e política. O ponto de partida seria reconhecer que as funções produtivas e reprodutivas da mulher estavam intimamente ligadas a condições políticas, econômicas, sociais, culturais, jurídicas, educacionais e religiosas (FIÚZA, 1997).

As mulheres deram contribuições históricas para a construção da sustentabilidade, dentre estas contribuições podemos citar Rachel Carson, bióloga marinha, autora do livro "Primavera Silenciosa". Obra de 1962, que contribuiu com o início do movimento ambientalista, com a denúncia dos efeitos danosos ao ambiente do DDT, pesticida que vinha sendo pulverizado em larga escala, principalmente nas lavouras americanas, provocando 
enormes impactos ambientais e na saúde humana. A obra recebeu este nome pelo desaparecimento de aves migratórias envenenadas com este princípio ativo. Denunciou um problema que incomodou o poderoso lobby da indústria química americana. Por conta disso, foi vítima de campanhas de difamação. Rachel resistiu e conquistou apoio de movimentos sociais que se articularam em defesa do banimento do DDT e de medidas regulatórias para o uso de pesticidas. Hoje o DDT é um pesticida proibido no mundo todo. Leff, (2002) considera esta obra como a grande responsável pelo surgimento da consciência ambiental na década de 60 .

Gro Brundtland, ex-primeira ministra da Noruega e ex-presidente da OMS (Organização Mundial da Saúde), foi considerada uma das três mulheres mais influentes do século XX. Designada pela ONU como chefe da comissão que pautou em 1987 a maior conferência da ONU até aquela data, a Conferência Internacional da ONU sobre Meio Ambiente e Desenvolvimento. Outra importante liderança mundial da sustentabilidade é Wangari Maathai, primeira ambientalista a conquistar o Prêmio Nobel da Paz, em 2004. Criadora do movimento Cinturão Verde (Green Belt Movement), promoveu o plantio de milhões de mudas de árvore no Quênia e países vizinhos, onde a demanda por lenha para a produção de energia reduziu drasticamente a área de florestas. Apenas no Quênia, a cobertura verde original foi reduzida a apenas $4 \%$. O movimento recrutou mulheres para o plantio e contou com o apoio da comunidade internacional. A recomposição das matas permitiu o retorno da fauna, a recarga dos aquíferos e melhorias nas condições de vida para milhões de pessoas.

Pode-se citar também Hazel Henderson, economista evolucionária, consultora em desenvolvimento sustentável, colunista sindicalizada e futurista de renome internacional. Fundadora da plataforma global de comunicação Ethical Markets Media, especialmente voltada para a sustentabilidade nas relações econômicas. Tornou-se uma das mais importantes pensadoras da atualidade, com trabalhos que sugerem a adoção de novos indicadores da economia, novas fórmulas para medir o PIB dos países. Levantou críticas ao modelo do PIB há pelo menos 20 anos. Segundo ela, o critério da riqueza per capita disfarça as desigualdades vigentes, pois a métrica do PIB considera apenas o resultado da atividade econômica sem levar em conta as chamadas externalidades: os custos social e ambiental envolvidos na 
produção da riqueza. Uma das líderes do Fórum Internacional sobre Globalização, ganhou o Prêmio Nobel Alternativo da Paz em 1993, feminista, ambientalista e Diretora da Fundação de Pesquisa para Ciência, Tecnologia e Ecologia, em Nova Déli, Vandana Shiva notabilizou-se pela luta em favor da biodiversidade e dos alimentos orgânicos. Criou na Índia uma organização que, entre outras atividades, recolhe diferentes tipos de sementes para proteção biogenética e uso gratuito pelas comunidades tradicionais. Vem denunciando o uso indiscriminado de pesticidas proibidos no hemisfério norte em países pobres, e o lobby dos transgênicos que impede a correta investigação de seus efeitos sobre a saúde humana e o meio ambiente.

Enquanto liderança nacional no âmbito da sustentabilidade pode-se citar Marina Silva, ex-líder seringueira, companheira de Chico Mendes, emergiu como liderança política do Acre para atuar como senadora da República, ministra do Meio Ambiente e candidata à Presidência da República conquistando um número significativo de votos. Reconhecida internacionalmente como legítima representante dos povos da floresta, Marina consagrou suas ações no Executivo e no Legislativo em favor das chamadas medidas estruturante para um modelo de gestão sustentável dos recursos. Conforme Viezzer (1996) diversos são os documentos, declarações e manifestos de mulheres e seus movimentos organizados que funcionam como porta-vozes da visão que as mesmas têm da necessidade de rever nossa maneira de pensar e tratar o mundo a partir de uma visão oposta à ciência e tecnologia patriarcais.

Em 1974, Françoise d'Eaubonne adotou pela primeira vez o termo ecofeminismo. Fez para representar o potencial que teriam as mulheres para encabeçarem uma revolução ecológica que construísse novas relações de gênero entre homens e mulheres e uma relação distinta entre os seres humanos e a natureza, (VALENCIA, 2008 apud MELLOR, 2000). O ecofeminismo pode ser definido como uma escola de pensamento que tem orientado movimentos ambientalistas e feministas, desde a década de 1970, em várias partes do mundo, procurando fazer uma interconexão entre a dominação da Natureza e a dominação das mulheres. Hoje em dia, é visto mais como uma corrente que trabalha com mulheres dentro do movimento ambientalista, do que propriamente parte do movimento feminista, que não compartilha totalmente de suas teses sobre a Natureza enquanto "princípio 
feminino" (SILIPRANDI, 2000).

Baseado nos princípios de que a exploração da mulher e a da natureza são produtos de um mesmo sistema em que o homem é identificado com a cultura e a mulher, com a natureza, o ecofeminismo parte dessa comparação para apontar a origem da hierarquia nas relações sociais, (AMARAL, 2011). Pelas bases conceituais do Ecofeminismo, o Meio Ambiente é considerado uma questão feminina e esta teoria é alicerçada na divisão social do trabalho, que segundo Engels em "A origem da Família, da propriedade e do Estado" observou que a "primeira divisão do trabalho ocorreu entre homem e mulher", tal observação foi feita ainda antes por Marx em "A ideologia Alemã", (ANDRADE, 2011). De acordo com Garcia (1992), o debate ecofeminista enfatiza o efeito das construções ideológicas nas relações de gênero e nas formas de ação em relação ao meio ambiente. Shiva (GARCIA, 1992 apud SHIVA 1988) expõe que a violência contra a mulher e a natureza não está baseada apenas na ideologia, mas também tem suas bases materiais. Assim, a relação das mulheres dos países subdesenvolvidos com a natureza vincula-se a uma dependência material na produção do seu sustento, de sua família e de sua comunidade. A destruição da natureza se torna desta forma a destruição das fontes de sobrevivência destas mulheres e de seus familiares e entes queridos.Além de diversas mulheres historicamente terem assumido o papel de líderes de movimentos em prol da solidariedade faz-se necessário uma análise da relação do gênero feminino com a natureza e a sustentabilidade, principalmente das mulheres situadas em ambientes de vulnerabilidade social e ambiental. Melo, (2010 p.1) descreve que:

\footnotetext{
No território rural a mulher trabalhadora da agricultura mantém íntima relação com a natureza. No rol dos recursos naturais, a água é um dos principais recursos por ela utilizado. O manejo, a conservação e a gestão, representam práticas adotadas pela mulher agricultora que cotidianamente utiliza a água para realizar atividades produtivas, bem como para o abastecimento da unidade familiar: o consumo doméstico.
}

Por outro lado, ao se discutir ou se propor políticas pública a estas comunidades, via de regra, as mulheres são excluídas da discussão. Os programas que integram as políticas públicas, na maioria das vezes, não consideram a existência das desigualdades sociais entre o masculino e o 
feminino, penalizando as mulheres, que ficam à margem do processo. De acordo com Morin (2000), a democratização das sociedades ocidentais foi um longo processo que continuou de maneira muito irregular em certas áreas, como o acesso das mulheres à igualdade com os homens no casal, no trabalho e na carreira pública.

A relação de gênero com a sustentabilidade segundo Castro e Abramovay (2005) não pode estar disposta sobre uma base essencialista, onde a mulher "naturalmente" seria mais dócil e sensível, capaz assim de meIhor cuidar e proteger o meio ambiente e, por esses motivos, empreender práticas mais sustentáveis. Ao contrário, pensamos que, em determinados grupos sociais as mulheres podem ser potencialmente impactadas pela degradação ambiental devido a construções sociais e históricas que, em determinados contextos, fazem com que elas cuidem mais das crianças, do espaço privado da casa, da produção e preparo de alimentos, assim como aos impactos na saúde, tal como o problema de saneamento. Contudo, com isso não se pretende promover uma vitimização unilateral da muIher, percebendo-a como um corpo único e homogêneo. Considera-se que as mulheres transitam por diferentes espaços e se relacionam de maneira diversa com o meio ambiente, sendo também causadoras de seu processo de degradação.

Desta forma, percebe-se que as mulheres urbanas se relacionam de forma diferente com o meio ambiente em relação às mulheres rurais e indígenas e, mesmo no interior de cada uma destas categorias, existem novas diferenciações (FRANÇA et al, 2011). Olhando-se sob o prisma do papel de consumo ante a degradação ambiental do planeta, torna-se relevante ressaltar que um novo fenômeno mundial chama a atenção de estudiosos de tendências do mercado: o crescente protagonismo das mulheres nas questões de consumo. Dos alimentos ao vestuário, da casa ao carro, dos bens culturais às viagens de férias, são elas que estão decidindo o presente e o futuro do consumo e, obviamente, o futuro da produção. Estudos recentes mostram que mais de $60 \%$ das decisões de compra são tomadas por mulheres (TEIXEIRA, 2012). 


\section{Considerações Finais}

Concorda-se com Viezzer (1996) ao afirmar que é fundamental termos presente que, ao trabalharmos sobre as questões de gênero, definitivamente não estamos tratando de algum assunto específico de mulheres, uma vez que "o problema não está apenas na mulher" quando se trata de temas como degradação ambiental e da qualidade de vida. É preciso compreender qual a inserção da mulher nesta perspectiva, seja enquanto agente contribuidor de processos insustentáveis, seja, como agente vítima das consequências de práticas insustentáveis em suas múltiplas dimensões.

Ao se discutir sustentabilidade sob a ótica de gênero faz-se necessário uma reflexão acerca da marginalização da mulher frente às múltiplas dimensões da sustentabilidade. Assim, é preciso discutir aspectos relacionados à: feminização da pobreza, observada na crescente proporção de mulheres em situação de pobreza; a desigualdade no acesso à educação e à capacitação; a desigualdade no acesso aos serviços de saúde; a violência contra a mulher; os efeitos dos conflitos armados sobre a mulher; a desigualdade quanto à participação nas estruturas econômicas, nas atividades produtivas e no acesso a recursos; a desigualdade em relação à participação no poder político; e nas instâncias decisórias; a insuficiência de mecanismos institucionais para a promoção do avanço da mulher; as deficiências na promoção e proteção dos direitos da mulher; o tratamento estereotipado dos temas relativos à mulher nos meios de comunicação e a desigualdade de acesso a esses meios; a desigualdade de participação nas decisões sobre o manejo dos recursos naturais e a proteção do meio ambiente; e a necessidade de proteção e promoção voltadas especificamente para os direitos da menina. Todos estes temas foram apontados como área de preocupação prioritária em políticas voltadas à promoção da equidade de gênero, pela Quarta Conferência Mundial da Mulher de Pequim (1995).

É emergente a necessidade de se construir formas mais harmônicas de relações sociais, no sentido de construir um novo conceito de ser e de conviver em nosso lar comum: o planeta terra. Para isso requer-se a construção de novas formas de organização e de convívio, fundamentadas no equilíbrio, harmonia e reciprocidade entre os seres humanos independente 
do gênero e deles com as demais espécies da natureza. Sachs (1999) afirma que um dos maiores desafios de nossa sociedade é o do reconhecimento de uma nova configuração política de se trabalhar na institucionalização de uma democracia verdadeiramente participativa em todos os níveis, no qual podemos incluir a participação de minorias sociais, étnicas e também a inclusão de gênero. Isto envolva a construção de processos plurais de democratização: o do acesso aos recursos acompanhado da consequente responsabilização pela construção de hábitos de vida que proporcionem a mínima degradação. Podendo-se complementar com Leis (1996) ao dizer que vivemos em uma humanidade que continua dependendo do amor e da fraternidade, da força de sua experiência espiritual, para viver com dignidade.

Leff (2002) afirma que o princípio da equidade é indissociável aos objetivos do desenvolvimento sustentável, além de ser um compromisso com as gerações futuras, apresenta-se como uma questão de solidariedade intrageracional, que implica tanto a distribuição dos custos ecológicos como o acesso dos atuais grupos sociais aos recursos ambientais do planeta. Neste prisma é fundamental a inserção de gênero no debate da justiça ambiental. Leff (2007) aponta que o maior desafio da educação na atualidade é o da responsabilidade da tarefa de coadjuvar um processo de construção de uma realidade ambiental, antes que a racionalidade dominante e a enganosa verdade do mercado globalizado nos arrastem para o abismo da morte entrópica do planeta e para a perda de sentido da existência humana e de educar para que os novos homens e mulheres do mundo sejam capazes de suportar a carga desta crise civilizatória e convertê-la no sentido de sua existência, para o reencantamento da vida e para a reconstrução do mundo. Nesta ótica emerge a importância da educação ambiental e a inclusão da perspectiva de gênero nos processos educativos, propondo a construção de novas relações a serem estabelecidas entre homens e mulheres nas sociedades e das sociedades com a natureza. O desafio maior consiste na definição de quais novos conhecimentos, habilidades e atitudes são necessárias incluir nos processos de educação ambiental para se atingir este pressuposto. 


\section{Referências}

AMARAL, A. C . Diversidade: um ponto de equilíbrio nas selvas de mata ou de pedra. 2011. Disponível em http://mercadoetico.terra.com.br/arquivo/ diversidade-um-ponto-de-equilibrio-nas-selvas-de-mata-ou-de-pedra. Acesso em: 04/07/2012.

ANDRADE, J. El-J.,O Marxismo e a questão feminina: as articulações entre gênero e classe no âmbito do feminismo revolucionário, tese de doutorado da USP, 2011. Disponível: www.teses.usp.br/teses/.../2011_ JoanaElJaickAndrade_VOrig.pdf. Acesso em: 05/07/2012.

CASTRO, M. G ,ABRAMOVAY, M..; Gênero e meio ambiente. São Paulo: Cortez; Brasília: UNESCO: UNICEF, 2005.

FIÚZA, A. L. C. Mulher e Ambientalismo, Estudos Sociedade e Agricultura, 9, outubro 1997: 178-189. Disponível em: http://168.96.200.17/ar/libros/brasil/ cpda/estudos/nove/fiuza9.htm. Acesso em: 03/07/2012.

FRANÇA, G. B.,(et al), Gênero e Território: a participação das mulheres nas práticas de sustentabilidade e a afirmação da territorialidade enquanto elemento de cidadania, 2011 http://apps.unibrasil.com.br/revista/index.php/ direito/article/viewFile/815/700. Acesso em: 28/06/2012.

GARCIA, S. M. Desfazendo os vínculos naturais entre gênero e meio ambiente. Estudos Feministas, R. J.., v.0, p.163-167, 1992. Disponível em: http:// www.sepm.gov.br/publicacoes-teste/publicacoes/2006/encontro-genero.pdf. Acesso em: 12/07/2012.

LAYRARGUES, P. P. Do ecodesenvolvimento ao desenvolvimento sustentável: evolução de um conceito? Proposta, 71, 1997 Estudos Sociedade e Agricultura, 9, outubro 1997: 178-189. http://bibliotecavirtual.clacso.org.ar/ ar/libros/brasil/cpda/estudos/nove/fiuza9.htm. Acesso em: 04/07/2012

LEFF, E. Ecologia, capital e cultura: racionalidade ambiental, democracia participativa e desenvolvimento sustentável. Coleção Sociedade e Ambiente 5. Blumenau/SC: Ed. Da FURB, 2000.

LEFF, E, Globalização, ambiente e sustentabilidade do desenvolvimento. Desenvolvimento e Meio Ambiente. n. 05, p. 15-95, jan./jun. 2002. Editora UFPR 
LEFF, E. La geopolítica de la biodiversidad y el desarrollo sustentable: Economización del mundo, racionalidad ambiental y reapropiación social de lanaturaleza. In: Debates Neoliberalismo de guerra y recursos naturales. OSAL. ano VI, n. 17. mai-ago 2005.

LEFF, E, Complejidad, racionalidad ambiental y diálogo de saberes: hacia una pedagogía ambiental. Desenvolvimento e Meio Ambiente, n. 16, p. 11-19, jul./ dez. 2007. Editora UFPR

LEIS, H. R. O labirinto: ensaios sobre o ambientalismo e globalização. São Paulo: Gaia; Blumenau: FURB, 1996.

MELO, L. A. A Mulher Agricultora: relação íntima com a água. Fazendo Gênero 9: Diásporas, Diversidades, Deslocamentos. ago/2010 http://www. fazendogenero.ufsc.br/9/resources/anais/1278442727.2010.pdf acessado em 02/07/2012.

MELLOR, M. Nature, $(R e)$ Production and Power. A Materialist Ecofeminist Perspectiva, enFredP. GaleyMichaelM'Gonigle(eds.), 2000pp. 105-120.http:// www.scielo.org.mx/scielo.php?pid=S0187-57952008000100010\&script=sci_ arttext acessado em 10/07/2012

MORIN, E. Os sete saberes necessários à educação do futuro. 2. ed. - São Paulo : Cortez; Brasília, DF : UNESCO, 2000.

SACHS, I. Estratégias de transição para o século XXI. Cadernos de desenvolvimento e meio ambiente. № 1, Curitiba: Ed. UFPR, 1999.

SHIVA, V. Staying Alive: Women, Ecology and Survival. Delhi: (ali for Women, London: Zed Books, 1988.

SILIPRANDI, E. Ecofeminismo: contribuições e limites para a abordagem de políticas ambientais. Agroecologia e Desenvolvimento Rural Sustentável. Porto Alegre, v.1, n1, jan./mar.2000

TEIXEIRA, I, As mulheres e o consumo sustentável. O conteúdo do EcoDesenvolvimento.org está sob Licença Creative Commons, http://www. ecodesenvolvimento.org.br/colunas/izabella-teixeira/solucoes-incompletaspara-a\#ixzz1zHRrGBgE acessado em 04/07/2012

VIEZZER, M.; RODRIGUES, C. L.; MOREIRA, T. Relações de gênero na educação ambiental. In: TRAJBER, R.; MANZOCHI, L. H. (Org.). Avaliando a Educação Ambiental no Brasil. Materiais Impressos. São Paulo: Gaia, 1996. 